IGUSABDER, 13 (2021): 71-87

\title{
Üniversite Öğrencilerinin Cinsel Mitlere Bakış Açısı ve ìlişkili Faktörler
}

\author{
Canan ÖRÜKLÜ*, Destina Gizem DAĞCI**, Sultan ÇAKMAK***
}

\section{Öz}

Amaç: Bu çalışmada Sağlık Bilimleri Yüksekokulunda okuyan öğrencilerin cinsel mitler ile ilgili düşüncelerini değerlendirmek amaçlanmıştır.

Yöntem: Çalışma bir vakıf üniversitesinde öğrenim gören 325 öğrenci ile yüz yüze görüşerek gerçekleştirilmiştir. Araştırmanın verileri “Tanıtıcı Bilgi Formu” ve "Cinsel Mitler Ölçeği” kullanılarak toplanmıştır. Verilerin analizinde tanımlayıcı istatistikler, Mann-Whitney U Testi, Kruskal-Wallis Testi ve Spearman rho korelasyon testi kullanılmıştır.

Bulgular: Çalışmaya katılan öğrencilerin \%69,5’inin kadın ve \%97,5’inin bekâr olduğu, \%69,8’inin şehirde yaşadığı belirlenmiştir. Ailesi Doğu Anadolu Bölgesi’nde yaşayan öğrencilerin cinsel yönelim ve mastürbasyon alt boyut puan ortalamaları anlamlı olarak yüksek bulunmuştur. Erkeklerin cinsel yönelim, toplumsal cinsiyet, yaş ve cinsellik, cinsel davranış, cinsel ilişki, cinsel memnuniyet alt boyut puan ortalamaları ve toplam cinsel mitler puanı kadınlara göre istatistiksel olarak anlamlı bulunmuştur ( $\mathrm{p}<0,05)$. Evlilik öncesi cinsel deneyim yaşanmasını uygun bulmayan öğrencilerin cinsel yönelim, mastürbasyon ve cinsel şiddet alt boyut puan ortalamaları ve toplam cinsel mitler puan ortalamaları evlilik öncesi cinsel deneyimi uygun bulan öğrencilere göre anlamlı olarak daha yüksek bulunmuştur.

\footnotetext{
Özgün Araştırma Makalesi (Original Research Article)

Geliş / Received: 27.12.2020 \& Kabul / Accepted: 24.01.2021

DOI: https://doi.org/10.38079/igusabder.845736

${ }^{*}$ Dr. Öğr. Üyesi, İstanbul Gelişim Üniversitesi, Sağllk Bilimleri Fakültesi, Hemşirelik Bölümü, İstanbul, Türkiye, E-posta: ckobak@gelisim.edu.tr ORCID https://orcid.org/o000-0002-95455176

** Arş. Gör., İstanbul Gelişim Üniversitesi, Sağlık Bilimleri Fakültesi, Hemşirelik Bölümü, İstanbul, Türkiye, E-posta: dgdagci@gelisim.edu.tr ORCID https://orcid.org/0000-0002-98445475

**** Arş. Gör., İstanbul Gelişim Üniversitesi, Sağlık Bilimleri Fakültesi, Hemşirelik Bölümü, İstanbul, Türkiye, sucakmak@gelisim.edu.tr ORCID https://orcid.org/o000-0001-8505-9586
} 
Sonuç: Erkeklerin cinsel mitlere inanma düzeyi kadınlardan fazladır. Bireyin ailesinin yaşadığı coğrafi bölge cinsel mitlere inanma durumunu etkilemektedir. Cinsel bilgilerin topluma doğru aktarılması amacıyla düzenlenen cinsel sağlık eğitimleri planlanırken kültürel ve coğrafi farklılıklar göz önünde bulundurulmalıdır.

Anahtar Kelimeler: Üniversite öğrencisi, cinsel mitler, bakış açısı.

\title{
University Students' Perspective on Sexual Myths and Related Factors
}

\begin{abstract}
Aim: This study aimed to evaluate the thoughts of the students studying at the School of Health Sciences on sexual myths.

Method: The study was carried out face-to-face with 325 students studying at a foundation university. The data of the study were collected using the "Introductory Information Form" and "Sexual Myths Scale”. Descriptive statistics, Mann-Whitney U Test, Kruskall-Wallis Test and Spearman rho correlation test were used to analyze the data.
\end{abstract}

Results: It was determined that $69,5 \%$ of the students participating in the study were female, $97,5 \%$ were single, and $69,8 \%$ lived in the city. The sexual orientation and masturbation subdimension mean scores of the students whose families live in the Eastern Anatolia Region were found to be significantly higher. Male sexual orientation, gender, age and sexuality, sexual behavior, sexual intercourse, sexual satisfaction sub-dimension mean scores and total sexual myths scores were statistically significant compared to women $(\mathrm{p}<0,05)$. Sexual orientation, masturbation and sexual violence sub-dimension mean scores and total sexual myths mean scores were found higher in students who find it inappropriate to have sexual experiences before marriage than others who find it appropriate.

Conclusion: Men are more likely to believe in sexual myths than women. The geographical region in which the individual's family lives affects their belief in sexual myths. Cultural and geographical differences should be taken into consideration while planning the sexual health trainings organized in order to transfer sexual information to the society correctly.

Keywords: University student, sexual myths, perspective.

\section{Giriş}

Cinsellik, insanlığın varoluşundan başlayıp günümüzde dahi araştırılmaya devam eden, önem derecesi yüksek konulardan biridir ${ }^{1}$. İnsanın yaşamını sürdürmesinde önemli bir rolü olmamakla birlikte, yaşam kalitesinin arttırılmasında ve sürdürülmesinde etkili 
olan cinsellik çok boyutlu bir kavram olarak ifade edilmektedir. Dünya Sağlık Örgütü (DSÖ)'ne göre cinsellik; hayat boyu insan olmanın merkezi bir yönü olan cinsiyeti, cinsel yönelimi, erotizme yakınlığı ve üremeyi kapsamaktadır. Cinsellik; arzular, fanteziler, inanç ve tavırlar, davranışlar, roller ve ilişkilerde deneyimlenerek ifade edilmektedir. Cinsellik tüm bu boyutları içerebilse de, hepsi bir arada bulunmayabilir².

Bireylerin cinsellikle ilgili tutum ve davranışlarının oluşmasında yetiştiği ailenin yapısı, arkadaş ve akran çevresi, eğitim düzeyi ve içinde bulunduğu kültür gibi faktörler etkili olmaktadır. Bireylerin cinselliğe bakış açısı, kültürler arası farklılıklar göstermekle birlikte aynı kültüre sahip bireylerde de farklılıklar da görülebilir3.

Türk Dil Kurumu (TDK), “mit” kelimesini geleneksel olarak yayllan veya toplumun hayal gücü etkisiyle biçim değiştiren alegorik bir anlatımı olan halk hikâyesi, efsaneleşen

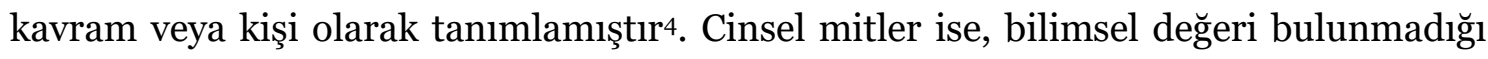
halde cinsellikle ilgili doğru olduğu düşünülen, kulaktan kulağa aktarılan, abartılı inanç ve düşünceler olarak tanımlanabilir5. Cinsel mitler, bireylerin cinsellikle ilgili konuları gerek aile gerekse toplum içinde konuşamayıp, kendilerini ifade edememelerine neden olmaktadır6-8.

Cinselliğin algılanma biçimini etkileyen en önemli unsurlar aile, eğitim, tıp, medya ve dini inanışlar olarak sayılabilir8,9. Yetişmekte olan çocukların yeterli ve doğru cinsel eğitim almasında ilk sorumluluk ailededir. Ancak yapılan çalışmalar cinsel bilgilerinin yetersizliği nedeniyle özellikle müslüman ailelerin bu konuda desteğe ihtiyac, duyduklarını göstermektedir8,10-12. Eğitim ve kültür düzeyleri fark etmeksizin pek çok ebeveyn cinsellik konusunda geleneksel bir tavır sergilemekte, cinsellik ile ilgili konuları bir tabu kabul etmekte ve çocukları ile cinselliğe dair konuşmalar yapmamaktadır. $\mathrm{Bu}$ sebeple; ailede başlaması gereken cinsellik eğitimi yeterince verilememektedir. Aynı geleneksel tavırlar okulda da sürdüğünden gençlerin çoğu eğitim hayatları süresince yeterli ve hatasız cinsel bilgiye ulaşamamaktadır. Buna ek olarak gençlerin arkadaş çevresi ve medyadan öğrendikleri hatalı bilgiler de cinsel mitlerin yaygınlaşmasına sebep olmaktadır ${ }^{13}$. Bunun sonucunda gençler cinsellikle ilgili dezenforme olmuş bilgiler edinip hatalı davranışlarda bulunabilmektedir. Oysa gençlerin ileriki zamanlarda aile hayatlarını, tercih ettikleri doğurganlık davranışlarını ve cinsel yaşamlarını doğrudan etkileyecek olan cinselliğe dair sahip oldukları bu bilgiler olacaktır ${ }^{14}$. Araştırmalar cinsel 
mitlerin toplumda eğitim düzeyi fark etmeksizin görülebildiğini, bu kişilerin arasında sağlık çalışanlarının da bulunduğunu göstermektedir ${ }^{3,15,16}$.

$\mathrm{Bu}$ bilgiler ışı̆̆ında, üniversitelerde geleceğin sağlık profesyonelleri olma yolunda öğrenim gören öğrencilerin cinsel mitlere bakış açısı toplumun doğru bilgilendirilmesi açısından oldukça önemlidir.

\section{Gereç ve Yöntem}

\section{Araştırmanın Amacı ve Şekli}

$\mathrm{Bu}$ çalışma üniversite öğrencilerinin cinsel mitlerle ilgili düşüncelerini belirlemek amacıyla tanımlayıcı-ilişki arayıcı türde yapılmıştır.

\section{Araştırma Soruları}

1. Üniversite öğrencilerinin cinsel mitleri onaylama durumları nelerdir?

2. Üniversite öğrencilerinin cinsel mitleri onaylama durumlarını etkileyen faktörler nelerdir?

\section{Araştırmanın Evren ve Örneklemi}

Araştırmanın evrenini İstanbul'da bulunan bir vakıf üniversitesinin 2018-2019 Eğitim Öğretim yılında Sağlık Bilimleri Yüksekokulunda öğrenim gören 6571 öğrenci oluşturmuştur. Bu öğrenciler arasından çalışmaya katılmaya gönüllü olan 325 öğrenci araştırma örneklemini oluşturmuştur.

\section{Veri Toplama Araçları ve Verilerin Toplanması}

Araştırmanın verileri, “Tanıtıcı Bilgi Formu” ve "Cinsel Mitler Ölçeği” kullanılarak toplanmiştır.

\section{Tanitıcı Bilgi Formu}

Literatür taraması sonucu oluşturulan form, toplamda iki bölümden oluşmaktadır. Birinci bölümde öğrencilerin sosyo-demografik özelliklerini belirleyen on sorudan, ikinci bölümü ise cinsel bilgi ve yaklaşımlarını değerlendiren sekiz sorudan oluşmaktadır. Veri toplamadan önce örneklemin \%10’u ile pilot çalışma yapılmıştır.

\section{Cinsel Mitler Ölçeği}

Gölbaşı ve arkadaşları tarafından geliştirilip güvenirlik ve geçerliliği yapılmış olan Cinsel Mitler Ölçeği, 5’li Likert tipi olan ve 28 maddeden oluşan bir ölçektir. Ölçeğin sekiz alt 
grubu (cinsel yönelim, toplumsal cinsiyet, yaş ve cinsiyet, cinsel davranış, mastürbasyon, cinsel şiddeti cinsel ilişki ve cinsel memnuniyet) bulunmaktadır. Ölçekten alınabilecek en düşük puan 28, en yüksek puan ise 140’tır. Ölçeğin kesme noktası bulunmamaktadır, elde edilen puanın artması cinsel mitlerin yaygın olduğunu göstermektedir ${ }^{17}$.

Çalışmaya başlamadan önce etik kurul izni ve kurum izni alınmıştır (İstanbul Gelişim Üniversitesi - 17.05.2019 / 2019-13-2). Ayrıca Prof. Dr. Zehra Gölbaşı'ndan e-posta yolu ile Cinsel Mitler Ölçeği’nin kullanım izni alınmıştır. Araştırmanın verileri, gönüllü katılım sağlayan, bilgilendirilmiş ve onamı alınmış üniversite öğrencileriyle yüz yüze görüşülerek toplanmıştır. Görüşme süresi ortalama 15 dakika sürmüştür.

\section{Verilerin Analizi}

Çalışma SPSS 22.0 Paket Programı kullanılarak yapılmıştır. Çalışmada alt boyut puanlarının ve toplam puanların değişkenlere göre tanımlayıcı istatistikleri verilmiş olup, örneklemdeki kişi sayısı (n), frekans (\%), ortalama, standart sapma ve minimum/maksimum değerleri kullanılmıştır. Veriler normal dağılıma sahip olmadığı için ( $\mathrm{p}<0,05)$ nonparametrik testler kullanılmıştır. İki bağımsız grup ortalamaları arasındaki farklılı̆̆ı ölçmek için Mann-Whitney U Testi kullanılmıştır. İkiden fazla bağımsız grup ortalamaları arasındaki farklılığı ölçmek için Kruskal-Wallis Testi kullanılmıştır. Sürekli değişkenler arasındaki ilişkiyi ölçmek için ise Spearman rho korelasyon testi kullanılmıştır. Tüm analizlerde anlamlılık düzeyi o,o5 olarak verilmiştir.

\section{Bulgular}

Araştırmaya katılan 325 öğrencinin \%69,54'ü kadın, \%30,46’sı erkektir ve \%97,54’ü bekardır. Üniversite öğrencilerinin \%48,31'si Hemşirelik, \%16,62'si Beslenme ve Diyetetik, \%4,31'ü Odyoloji, \%o,31’i Çocuk Gelişimi, \%8,31'si Sosyal Hizmet, \%12,31’i Dil ve Konuşma Terapisi, \%2,46'sı Ortez-Protez ve \%7,38’i Ergoterapi bölümünde okumaktadır. Öğrencilerin \%69,8’inin şehirde yaş,adığı, ailelerin yaşadığı coğrafi bölgeler arasında ise ilk sırada Marmara Bölgesi (\%42,2)'nin daha sonra Güneydoğu Anadolu Bölgesi $(\% 19,4)$ 'nin olduğu belirlenmiştir. Anne eğitim düzeylerine bakıldığında \%29,5' inin ilkokul mezunu, \%14,4'ünün lisans ve üstü mezunu olduğu ve \%5,5’inin okuma yazma bilmediği belirlenmiş, baba eğitim düzeyleri incelendiğinde ise \%30,5’inin lise mezunu, \%19,1’inin lisans ve üstü mezunu olduğu \%1,8’inin ise okuma yazma bilmediği görülmüştür (Tablo 1). 
Tablo 1. Öğrencilerin Tanıtıcı Özellikleri $(n=325)$

\begin{tabular}{|c|c|c|c|}
\hline Özellikler & & $\mathbf{n}$ & $\%$ \\
\hline \multirow[t]{3}{*}{ Yaş } & $17-20$ & 103 & 31,7 \\
\hline & $21-24$ & 199 & 61,2 \\
\hline & 25 ve üzeri & 23 & 7,1 \\
\hline \multirow[t]{2}{*}{ Cinsiyet } & Kadın & 226 & 69,54 \\
\hline & Erkek & 99 & 30,46 \\
\hline \multirow[t]{8}{*}{ Okuduğu Bölümm } & Hemşirelik & 157 & 48,31 \\
\hline & Beslenme ve Diyetetik & 54 & 16,62 \\
\hline & Odyoloji & 14 & 4,31 \\
\hline & Çocuk Gelişimi & 1 & 0,31 \\
\hline & Sosyal Hizmet & 27 & 8,31 \\
\hline & Dil ve Konuşma Terapisi & 40 & 12,31 \\
\hline & Ortez-Protez & 8 & 2,46 \\
\hline & Ergoterapi & 24 & 7,38 \\
\hline \multirow[t]{2}{*}{ Medeni Durum } & Evli & 8 & 2,46 \\
\hline & Bekar & 317 & 97,54 \\
\hline \multirow[t]{7}{*}{ Ailenin Yaşadığı Coğrafi Bölge } & Marmara & 137 & 42,15 \\
\hline & İç Anadolu & 17 & 5,23 \\
\hline & Ege & 23 & 7,08 \\
\hline & Doğu & 28 & 8,62 \\
\hline & Güneydoğu Anadolu & 63 & 19,38 \\
\hline & Karadeniz & 29 & 8,92 \\
\hline & Akdeniz & 28 & 8,62 \\
\hline \multirow[t]{8}{*}{ Cinsellikle ilgili bilgileri kimden/nereden aldını?? } & Annem & 67 & 20 \\
\hline & Babam & 15 & 4,6 \\
\hline & Kardeşlerim & 21 & 6,5 \\
\hline & Okuldan & 126 & 38,8 \\
\hline & Arkadaşlarımdan & 143 & 44 \\
\hline & İletişim Araçlarından & 203 & 62,5 \\
\hline & Sağlık Personelinden & 71 & 21,8 \\
\hline & Hiç Bilgi Almadım & 25 & 7,7 \\
\hline \multirow[t]{7}{*}{ Cinsellikle ilgili konuları kiminle konuşuyorsunuz? } & Annemle & 88 & 27,1 \\
\hline & Babamla & 11 & 3,4 \\
\hline & Kardeşlerimle & 33 & 10,2 \\
\hline & Öğretmenimle & 13 & 4,0 \\
\hline & Arkadaşlarımla & 169 & 52,0 \\
\hline & Doktorumla & 78 & 24,0 \\
\hline & Hiç Kimseyle & 83 & 25,5 \\
\hline
\end{tabular}


Araştırmaya katılan öğrencilerin toplam cinsel mitler puan ortalaması 61,02 $\pm 19,10$ 'dur. Öğrencilerin cinsiyetlerine göre toplam cinsel mit puanı incelendiğinde erkeklerin toplam cinsel mit puanı kadın bireylere göre yüksek oranda anlamlı bulunmuştur. Yaş, medeni durum, okudukları bölüm gibi diğer tanıtıcı özellikleri öğrencilerin cinsel mitler toplam puanında anlamlı olarak fark oluşturmamıştır (Tablo 2).

Tablo 2. Öğrencilerin Cinsel Mitler Ölçeği'nden Aldığı Puanlar ( $n=325)$

\begin{tabular}{|l|c|c|}
\hline Cinsel Mitler Ölçeği & Ort \pm SD & Min-Max \\
\hline Cinsel Yönelim & $14,13 \pm 5,37$ & $5-25$ \\
\hline Toplumsal Cinsiyet & $11,16 \pm 5,27$ & $6-30$ \\
\hline Yaş ve Cinsellik & $8,30 \pm 3,68$ & $4-20$ \\
\hline Cinsel Davranış & $5,40 \pm 3,04$ & $3-15$ \\
\hline Masturbasyon & $4,79 \pm 2,30$ & $2-10$ \\
\hline Cinsel Şiddet & $6,73 \pm 3,12$ & $4-20$ \\
\hline Cinsel İlişki & $5,35 \pm 2,05$ & $2-10$ \\
\hline Cinsel Memnuniyet & $5,16 \pm 2,02$ & $2-10$ \\
\hline Toplam Cinsel Mit Puanı & $\mathbf{6 1 , 0 2 \pm 1 9 , 1 0}$ & $\mathbf{2 8 - 1 3 2}$ \\
\hline
\end{tabular}

Ailelerin yaşadığı coğrafi bölgeler ile cinsel mitler toplam puan ortalamaları arasında anlamlı bir fark bulunamamış $(\mathrm{p}<0,005)$ ancak cinsel yönelim ve mastürbasyon alt boyutu puan ortalamalarının arasında anlamlı düzeyde farklılık bulunmuştur. Buna göre her iki alt boyut için de Doğu Anadolu Bölgesi diğer bölgelere göre anlamlı olarak daha yüksek bulunmuştur. Cinsel yönelim alt boyut puan ortalamaları Doğu Anadolu Bölgesi

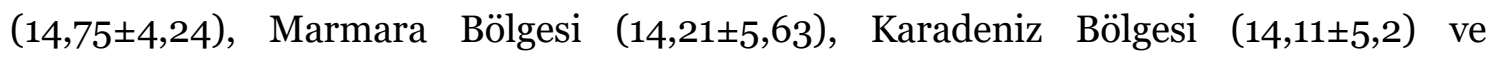
mastürbasyon alt boyut puan ortalamaları Doğu Anadolu Bölgesi $(5,75 \pm 2,18)$ ve Güneydoğu Anadolu Bölgesi $(5,47 \pm 2,59)$ olarak belirlenmiştir. Öğrencilerin cinsellik ile ilgili bilgi düzeylerini yeterli bulma durumu incelendiğinde \%65,54'ünün yeterli bulduğu \%34,46’sının ise yeterli bulmadığı belirlenmiştir. Cinsellik ile ilgili bilgi düzeyini yeterli bulmayanların mastürbasyon puan ortalamaları $(5,42 \pm 2,25)$ bilgi düzeyini yeterli bulanlara göre $(4,47 \pm 2,27)$ anlamlı olarak daha yüksektir. Öğrencilerin \%71,69’u evlilik öncesi cinsel ilişkiyi doğru bulmadığını belirtmiştir. Evlilik öncesi cinsel ilişkiyi uygun 
bulmayan öğrencilerin toplam cinsel mitler puan ortalamaları, cinsel yönelim puan ortalamaları, mastürbasyon puan ortalamaları ve cinsel şiddet puan ortalamaları evlilik öncesi cinsel ilişkiyi doğru bulduğunu belirten öğrencilerin puan ortalamalarına göre anlamlı olarak daha yüksek bulunmuştur. Öğrencilerin \%88,92'si cinselliğin yalnızca partner ile yaşanması gerektiğini düşünmektedir. Cinselliğin sadece partner ile yaşanması gerektiğini düşünmeyen öğrencilerin toplumsal cinsiyet puan ortalamaları $(13,00 \pm 5,14)$ sadece partner ile yaşanması gerektiğini düşünen öğrencilerin toplumsal cinsiyet puan ortalamalarından $(10,94 \pm 5,26)$ anlamlı olarak daha yüksek bulunmuştur (Tablo 3, Tablo 4).

Tablo 3. Öğrencilerin Cinsiyeti ile Cinsel Mitler Ölçeği Alt Boyutları ve Toplam ile Değerlendirilmesi $(\mathrm{n}=325)$

\begin{tabular}{|c|c|c|c|c|c|c|}
\hline & Cinsiyet & n (\%) & Ort \pm SD & Min-Max & $\begin{array}{l}\text { Mann- } \\
\text { Whitney U } \\
\text { (Z) }\end{array}$ & $\mathbf{p}$ \\
\hline \multirow{2}{*}{ Cinsel Yönelim } & Kadın & $226(69,54)$ & $13,2 \pm 5,12$ & $5-25$ & \multirow{2}{*}{$-4,726$} & \multirow{2}{*}{,OOO* } \\
\hline & Erkek & $99(30,46)$ & $16,29 \pm 5,36$ & $5-25$ & & \\
\hline \multirow{2}{*}{ Toplumsal Cinsiyet } & Kadın & $226(69,54)$ & $9,95 \pm 4,42$ & $6-30$ & \multirow{2}{*}{$-6,109$} & \multirow{2}{*}{,000* } \\
\hline & Erkek & $99(30,46)$ & $13,95 \pm 6,01$ & $6-30$ & & \\
\hline \multirow{2}{*}{ Yaş ve Cinsellik } & Kadın & $226(69,54)$ & $7,94 \pm 3,39$ & $4-20$ & \multirow{2}{*}{$-2,262$} & \multirow{2}{*}{,024* } \\
\hline & Erkek & $99(30,46)$ & $9,15 \pm 4,18$ & $4-20$ & & \\
\hline \multirow{2}{*}{ Cinsel Davranış } & Kadın & $226(69,54)$ & $4,96 \pm 2,67$ & $3-15$ & \multirow{2}{*}{$-4,451$} & \multirow{2}{*}{,oö* } \\
\hline & Erkek & $99(30,46)$ & $6,68 \pm 3,58$ & $3-15$ & & \\
\hline \multirow{2}{*}{ Mastürbasyon } & Kadın & $226(69,54)$ & $4,70 \pm 2,29$ & $2-10$ & \multirow{2}{*}{$-1,244$} & \multirow{2}{*}{,213 } \\
\hline & Erkek & $99(30,46)$ & $5,02 \pm 2,35$ & $2-10$ & & \\
\hline \multirow{2}{*}{ Cinsel Şiddet } & Kadın & $226(69,54)$ & $6,23 \pm 2,73$ & $4-20$ & \multirow{2}{*}{$-4,281$} & \multirow{2}{*}{,ooo* } \\
\hline & Erkek & $99(30,46)$ & $7,91 \pm 3,66$ & $4-20$ & & \\
\hline \multirow{2}{*}{ Cinsel İlişki } & Kadın & $226(69,54)$ & $5,19 \pm 2,03$ & $2-10$ & \multirow{2}{*}{$-2,409$} & \multirow{2}{*}{,016* } \\
\hline & Erkek & $99(30,46)$ & $5,75 \pm 2,08$ & $2-10$ & & \\
\hline \multirow{2}{*}{ Cinsel Memnuniyet } & Kadın & $226(69,54)$ & $4,93 \pm 2,01$ & $2-10$ & \multirow{2}{*}{$-3,476$} & \multirow{2}{*}{,oo1* } \\
\hline & Erkek & $99(30,46)$ & $5,72 \pm 1,98$ & $2-10$ & & \\
\hline \multirow{2}{*}{$\begin{array}{l}\text { Toplam Cinsel Mit } \\
\text { Puanı }\end{array}$} & Kadın & $226(69,54)$ & $54,58 \pm 15,64$ & $27-125$ & \multirow{2}{*}{$-5,301$} & \multirow{2}{*}{,000* } \\
\hline & Erkek & $99(30,46)$ & $67,79 \pm 21,45$ & 27-127 & & \\
\hline
\end{tabular}


Tablo 4. Öğrencilerin Tanıtıcı Özellikleri ile Cinsel Mitler Ölçeği Puan Ortalamasının Dağılımı ( $\mathrm{n}=325)$

\begin{tabular}{|c|c|c|c|c|c|c|c|c|c|c|c|c|}
\hline \multirow[t]{2}{*}{ Özellikler } & & \multirow[b]{2}{*}{$\mathbf{n}$} & \multicolumn{2}{|c|}{$\begin{array}{c}\text { Toplam } \\
\text { Cinsel Mit }\end{array}$} & \multicolumn{2}{|c|}{$\begin{array}{c}\text { Cinsel } \\
\text { Yönelim }\end{array}$} & \multicolumn{2}{|c|}{ Mastürbasyon } & \multicolumn{2}{|c|}{$\begin{array}{l}\text { Cinsel } \\
\text { Şiddet }\end{array}$} & \multicolumn{2}{|c|}{$\begin{array}{c}\text { Toplumsal } \\
\text { Cinsiyet }\end{array}$} \\
\hline & & & $\begin{array}{l}\text { Ort } \\
\pm \text { SD }\end{array}$ & $\begin{array}{c}\text { Min } \\
- \\
\text { Max }\end{array}$ & $\begin{array}{c}\text { Ort } \\
\pm \text { SD }\end{array}$ & $\begin{array}{c}\text { Min } \\
- \\
\text { Max }\end{array}$ & $\begin{array}{c}\text { Ort } \\
\pm \text { SD }\end{array}$ & $\begin{array}{l}\text { Min - } \\
\text { Max }\end{array}$ & $\begin{array}{c}\text { Ort } \\
\pm \text { SD }\end{array}$ & $\begin{array}{c}\text { Min } \\
- \\
\text { Max }\end{array}$ & $\begin{array}{c}\text { Ort } \\
\pm \text { SD }\end{array}$ & $\begin{array}{c}\text { Min } \\
- \\
\text { Max }\end{array}$ \\
\hline \multirow{7}{*}{$\begin{array}{l}\text { Ailenin } \\
\text { Yaşadığı } \\
\text { Coğrafi } \\
\text { Bölge }\end{array}$} & Marmara & 137 & $\begin{array}{r}56,79 \\
\pm 17,46\end{array}$ & $\begin{array}{l}27- \\
126\end{array}$ & $\begin{array}{l}14,21 \\
\pm 5,63\end{array}$ & $5^{-25}$ & $\begin{array}{r}4,64 \\
\pm 2,27\end{array}$ & $2-10$ & $\begin{array}{c}6,16 \\
\pm 2,71\end{array}$ & $4-20$ & $\begin{array}{c}10,71 \\
\pm 5,02\end{array}$ & $6-26$ \\
\hline & İç Anadolu & 17 & $\begin{array}{c}60,18 \\
\pm 18,58\end{array}$ & $\begin{array}{c}27- \\
91\end{array}$ & $\begin{array}{l}14,06 \\
\pm 6,27\end{array}$ & $5^{-25}$ & $\begin{array}{l}4,42 \\
\pm 2,4\end{array}$ & $2-9$ & $\begin{array}{c}7,48 \\
\pm 3,63\end{array}$ & $4-16$ & $\begin{array}{l}11,65 \\
\pm 4,32\end{array}$ & $6-19$ \\
\hline & Ege & 23 & $\begin{array}{c}52,35 \\
\pm 18,95\end{array}$ & $\begin{array}{l}27- \\
95\end{array}$ & $\begin{array}{c}11,74 \\
\pm 4,65\end{array}$ & $5-21$ & $\begin{array}{c}4,27 \\
\pm 1,58\end{array}$ & $2-7$ & $\begin{array}{c}6,74 \\
\pm 3,13\end{array}$ & 4-15 & $\begin{array}{l}9,96 \\
\pm 4,5\end{array}$ & $6-21$ \\
\hline & D. Anadolu & 28 & $\begin{array}{l}60,58 \\
\pm 11,47\end{array}$ & $\begin{array}{l}37^{-} \\
90\end{array}$ & $\begin{array}{l}14,75 \\
\pm 4,24\end{array}$ & $8-25$ & $\begin{array}{c}5,75 \\
\pm 2,18\end{array}$ & $2-10$ & $\begin{array}{c}7,15 \\
\pm 2,47\end{array}$ & 4-12 & $\begin{array}{l}11,04 \\
\pm 4,36\end{array}$ & $6-21$ \\
\hline & G. Anadolu & 63 & $\begin{array}{c}64,91 \\
\pm 22,91\end{array}$ & $\begin{array}{l}29- \\
127\end{array}$ & $\begin{array}{l}15,54 \\
\pm 4,88\end{array}$ & $7-25$ & $\begin{array}{c}5,47 \\
\pm 2,59\end{array}$ & $2-10$ & $\begin{array}{c}7,74 \\
\pm 3,86\end{array}$ & $4-20$ & $\begin{array}{l}12,86 \\
\pm 6,73\end{array}$ & $6-30$ \\
\hline & Karadeniz & 29 & $\begin{array}{l}60,07 \\
\pm 17,1\end{array}$ & $\begin{array}{l}35^{-} \\
105\end{array}$ & $\begin{array}{l}14,11 \\
\pm 5,2\end{array}$ & $5^{-24}$ & $\begin{array}{l}4,35 \\
\pm 2,11\end{array}$ & $2-10$ & $\begin{array}{l}6,69 \\
\pm 3,3\end{array}$ & $4-16$ & $\begin{array}{c}11,21 \\
\pm 5,48\end{array}$ & $6-26$ \\
\hline & Akdeniz & 28 & $\begin{array}{c}53,97 \\
\pm 17,49\end{array}$ & $\begin{array}{l}27- \\
89\end{array}$ & $\begin{array}{l}12,08 \\
\pm 5,62\end{array}$ & $5-25$ & $\begin{array}{c}4,22 \\
\pm 2,12\end{array}$ & $2-10$ & $\begin{array}{c}6,54 \\
\pm 2,97\end{array}$ & $4-16$ & $\begin{array}{l}10,43 \\
\pm 3,96\end{array}$ & $6-20$ \\
\hline $\boldsymbol{p}$ & & & \multicolumn{2}{|c|}{$\mathrm{p}=0,053$} & \multicolumn{2}{|c|}{$\mathrm{p}=0,039^{*}$} & \multicolumn{2}{|c|}{$\mathrm{p}=0,035^{*}$} & \multicolumn{2}{|c|}{$\mathrm{p}=0,071$} & \multicolumn{2}{|c|}{$\mathrm{p}=0,322$} \\
\hline \multirow{2}{*}{$\begin{array}{l}\text { Cinsellik ile } \\
\text { İlgili Bilgi } \\
\text { Düzeyini } \\
\text { Yeterli } \\
\text { Bulma }\end{array}$} & Evet & 213 & $\begin{array}{c}58,68 \\
\pm 20,08\end{array}$ & $\begin{array}{l}27^{-} \\
127\end{array}$ & $\begin{array}{l}14,16 \\
\pm 5,65\end{array}$ & $5^{-25}$ & $\begin{array}{c}4,47 \\
\pm 2,27\end{array}$ & $2-10$ & $\begin{array}{c}6,75 \\
\pm 3,32\end{array}$ & $4-20$ & $\begin{array}{c}11,5 \\
\pm 5,62\end{array}$ & $6-30$ \\
\hline & Hayır & 112 & $\begin{array}{c}58,46 \\
\pm 15,50\end{array}$ & $\begin{array}{l}29- \\
125\end{array}$ & $\begin{array}{l}14,10 \\
\pm 4,85\end{array}$ & $6-25$ & $\begin{array}{c}5,42 \\
\pm 2,25\end{array}$ & $2-10$ & $\begin{array}{c}6,73 \\
\pm 2,77\end{array}$ & $4-20$ & $\begin{array}{l}10,54 \\
\pm 4,51\end{array}$ & $6-30$ \\
\hline$p$ & & & \multicolumn{2}{|c|}{$\mathrm{p}=0,629$} & \multicolumn{2}{|c|}{$\mathrm{p}=0,935$} & \multicolumn{2}{|c|}{$\mathrm{p}=0,000^{*}$} & \multicolumn{2}{|c|}{$\mathrm{p}=0,322$} & \multicolumn{2}{|c|}{$\mathrm{p}=0,363$} \\
\hline \multirow{2}{*}{$\begin{array}{l}\text { Evlilik } \\
\text { Öncesi } \\
\text { Cinsel } \\
\text { Deneyim } \\
\text { Yaşanmasını } \\
\text { Uygun } \\
\text { Bulma }\end{array}$} & Evet & 92 & $\begin{array}{c}54,29 \\
\pm 19,73\end{array}$ & $\begin{array}{l}27- \\
126\end{array}$ & $\begin{array}{l}12,08 \\
\pm 5,39\end{array}$ & $5^{-25}$ & $\begin{array}{c}3,98 \\
\pm 2,08\end{array}$ & $2-10$ & $\begin{array}{c}6,28 \\
\pm 3,22\end{array}$ & $4-20$ & $\begin{array}{l}10,89 \\
\pm 4,99\end{array}$ & $6-24$ \\
\hline & Hayır & 233 & $\begin{array}{l}60,31 \\
\pm 17,9\end{array}$ & $\begin{array}{l}27- \\
127\end{array}$ & $\begin{array}{l}14,95 \\
\pm 5,16\end{array}$ & $5^{-25}$ & $\begin{array}{c}5,12 \\
\pm 2,32\end{array}$ & $2-10$ & $\begin{array}{c}6,92 \\
\pm 3,09\end{array}$ & $4-20$ & $\begin{array}{l}11,28 \\
\pm 5,39\end{array}$ & $6-30$ \\
\hline $\boldsymbol{p}$ & & \multicolumn{3}{|c|}{$\mathrm{p}=0,001^{*}$} & \multicolumn{2}{|c|}{$\mathrm{p}=0,000^{*}$} & \multicolumn{2}{|c|}{$\mathrm{p}=0,000^{*}$} & \multicolumn{2}{|c|}{$\mathrm{p}=0,013^{*}$} & \multicolumn{2}{|c|}{$\mathrm{p}=0,554$} \\
\hline \multirow{2}{*}{$\begin{array}{l}\text { Cinselliğin } \\
\text { Yalnızca } \\
\text { Partner ile } \\
\text { Yaşanması } \\
\text { Gerektiğini } \\
\text { Düşünme }\end{array}$} & Evet & 289 & $\begin{array}{c}58,05 \\
\pm 18,36\end{array}$ & $\begin{array}{l}27- \\
127\end{array}$ & $\begin{array}{l}14,05 \\
\pm 5,36\end{array}$ & $5^{-25}$ & $\begin{array}{c}4,75 \\
\pm 2,28\end{array}$ & $2-10$ & $\begin{array}{c}6,63 \\
\pm 3,07\end{array}$ & $4-20$ & $\begin{array}{l}10,94 \\
\pm 5,26\end{array}$ & $6-30$ \\
\hline & Hayır & 36 & $\begin{array}{c}63,06 \\
\pm 20,13\end{array}$ & $\begin{array}{l}27- \\
126\end{array}$ & $\begin{array}{l}14,87 \\
\pm 5,51\end{array}$ & $5^{-25}$ & $\begin{array}{c}5,14 \\
\pm 2,55\end{array}$ & $2-10$ & $\begin{array}{l}7,59 \\
\pm 3,51\end{array}$ & $4-20$ & $\begin{array}{l}13,00 \\
\pm 5,14\end{array}$ & $6-22$ \\
\hline$p$ & & & \multicolumn{2}{|c|}{$\mathrm{p}=0,141$} & \multicolumn{2}{|c|}{$\mathrm{p}=0,432$} & \multicolumn{2}{|c|}{$\mathrm{p}=0,531$} & \multicolumn{2}{|c|}{$\mathrm{p}=0,069$} & \multicolumn{2}{|c|}{$\mathrm{p}=0,010^{*}$} \\
\hline
\end{tabular}




\section{Tartışma}

$\mathrm{Bu}$ çalışmada öğrencilerin Cinsel Mitler Ölçeğinden aldı̆̆ı puan ortalaması $61,02 \pm 19,10$ 'dur. Üniversite öğrencilerinde cinsel mit inanç düzeyini inceleyen Evcili ve

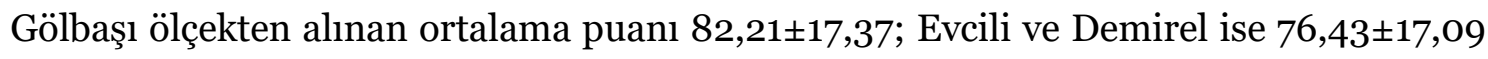
olarak hesaplamıştır ${ }^{18,19}$. Bu veriler öğrencilerin cinsellik ile ilgili orta düzeyde bilgi sahibi olduğunu göstermektedir. Öğrencilerin yaş, bölüm, medeni durum, gelir durumu, yaşanılan yer, ilişki durumu ve süresinin ölçekten alınan puanları etkilemediği görülmüştür. Cinsellik, kültür yapısı ve inanç ile şekillenen psikofizyolojik bir olgudur ve bu nedenle kişiden kişiye farklılıklar gösterebilmektedir²0 . Aker ve arkadaşlarının yaptığı araştırmada öğrencilerin aldıkları ölçek puanları ile medeni durum, yaşanılan coğrafi bölge, ikamet yeri ve romantik ilişki yaşama durumu arasında anlamlı bir farklılık saptanmamıştır ${ }^{21}$. Mevcut birkaç çalışmada öğrencilerin yaşadığı coğrafi bölgelerin cinsel mit inanışları üzerinde etkili olduğu; ergenlik öncesinde köy veya ilçe merkezinde yaşayan öğrencilerin cinsel mitlere olan inanç düzeyinde artış görüldüğü belirtilmiştiri18,22,23. Ziya çalışmasında ailelerin yaşadığı coğrafi bölgelerin öğrencilerin cinsel mit inanış düzeylerinde etkili olmadığını ifade ederken bu çalışmada Doğu ve Güneydoğu bölgelerinde yaşayan ailelere sahip üniversite öğrencileri ile ailesi diğer bölgelerde yaşayan öğrenciler karşılaştırıldığında "Cinsel Yönelim” ve "Mastürbasyon" alt boyutlarında istatistiksel olarak anlamlı bir artış olduğu görülmüşsür ${ }^{24}$.

Evcili ve Gölbaşı cinsellik ile ilgili yeterli düzeyde bilgi sahibi olduğunu düşünen öğrencilerin ölçekten aldıkları ortalama puanları daha düşük bulmuştur ${ }^{18}$. Evcili ve Demirel'in çalışmasında cinsellik ile ilgili yeterli bilgi düzeyine sahip olduğunu düşünen öğrencilerde Cinsel Mitler Ölçeğinden alınan puan ortalaması ise daha yüksek bulunmuştur ${ }^{19}$. Aker ve Böke ise eğitim düzeyinin artmasıyla cinsel mitlere olan inanç düzeyinin de artış gösterdiğini belirtmiştir ${ }^{25}$. Bu çalışmada ise cinsellik ile ilgili bilgi düzeyini yeterli bulmayan öğrencilerde "Mastürbasyon” alt boyut puanı ortalaması anlamlı farklılık göstermiştir.

Bu çalışma, diğer çalışmalarda olduğu gibi erkek öğrencilerin kız öğrencilere oranla daha fazla cinsel mit inanışına sahip olduğunu göstermiştiri18,21,22,26-28. Ataerkil toplumlarda erkeklerin merkezi bir role sahip olması, kadınların ise ikincil konumda yer alması erkeklere farklı ayrıcalıklar sunmaktadır. Bu ayrıcalıklar erkeklerin daha fazla cinsel mitlere inanmasını tetikleyebilmektedir. Bu tür toplumlarda erkek cinselliği otoriter ve 
vahşi, kadın cinselliği ise pasif ve itaatkâr olarak aksettirilmektedir. Bu tür ortamlarda yaşayan erkekler, kadın kimliği ve cinselliği hakkında olumsuz davranış biçimleri sergilemektedir29,30. Bu çalışmada "Toplumsal Cinsiyet” ve "Cinsel Davranış" alt boyut puanlarının erkek öğrencilerde anlamlı düzeyde yüksek bulunması olumsuz tutum ve davranış geliştirildiğini göstermektedir.

Torun ve arkadaşlarının yaptığı çalışmada bu çalışmanın verilerini destekler şekilde anne ve baba eğitim düzeyinin öğrencilerin cinsel mitlere inanış düzeylerini etkilemediği görülmüştür²2 ${ }^{2}$ Yapılan bazı araştırmalarda ise anne eğitim düzeyi ve baba eğitim düzeyi ile cinsel mitler arasında negatif bir ilişki olduğu belirtilmiştirir18,19,21.

Araştırma sonucunda elde edilen verilere göre "Yaş ve Cinsellik" alt boyutlarında erkek öğrencilerin aldıkları puanlar anlamlı olarak daha yüksek bulunmuştur. Bu alt boyut maddeleri incelendiğinde yaşlılığın özellikle de menopozun cinselliği sonlandırdığı inancı hakimdir. Yılmaz ve Karataş’ın yaptı̆̆ı araştırmada her beş öğrenciden biri yaşlılıkla birlikte gelen hastalıklar nedeniyle cinsel aktivitenin azalması ve partnerlerden birinin cinselliğe ilgi duymaması gerektiğini düşünmektedir ${ }^{1}$. Yine aynı çalışmada öğrencilerin bir kısmı sadece erkeklerin mastürbasyon yapabileceğini, evli ve kadınların ise mastürbasyon yapmaması gerektiğini ifade etmiştir. Constanza ve arkadaşları ise yaptığı çalışmada erkeklerin kadınlara oranla mastürbasyona daha olumlu yaklaştığını belirtmiştir32 ${ }^{2}$ Bu çalışmada da evlilik öncesi cinsel deneyimi uygun bulmayanlarda "Mastürbasyon" alt boyut puanları anlamlı bir farklılık göstermiştir.

Eşcinselliği bir hastalık olarak görmek en yaygın cinsel mitler arasında yer almaktadır33. “Cinsel Yönelim” alt boyutundan alınan puan ortalaması erkek öğrencilerde anlamlı olarak daha yüksek bulunmuştur. Bu sonuç erkeklerin eşcinsellik konusunda kadınlardan daha fazla olumsuz tutumlara sahip olduğunu göstermektedir34.

Erkeklerin kadınlardan daha yüksek puan aldığı bir başka alt boyut ise "Cinsel Şiddet”tir. Bu sonuç erkek öğrencilerin cinsel saldırı hakkında düşük bilgi düzeyine sahip olduğunu göstermiştir35.

Yapılan birçok araştırmada öğrenciler cinsel bilgi kaynaklarını, sıralaması değişmekle birlikte arkadaşlar, internet, televizyon, kitap/dergi/gazete olarak belirtmişlerdir ${ }^{18,36-38}$. Teknolojinin gelişmesiyle son yıllarda milyonlarca kişi bilgi almak için dijital platformları kullanmaktadır39. Kolay ulaşılabilir olması nedeniyle öğrencilerin cinsellik 
hakkında bilgi edinmeye çalıştığı ve büyük bir kısmını güvensiz kaynakların oluşturduğu bu platformlar cinsel mitlere olan inanç düzeyini artırabilmekte ve yanlış/riskli cinsel tutum ve davranışlara neden olabilmektedir ${ }^{40}$. Aygin ve arkadaşlarının yaptığı çalışmada öğrencilerin cinsellikle ilgili bilgileri medya aracılığıla öğrendiği ifade edilmiştir ${ }^{41}$. Yılmaz ve Karataş’a göre her dört öğrenciden biri ergenlik döneminde eğitim amaçlı pornografik film izlenebileceğini ancak belirli bir yaştan sonra buna son verilmesini, son verilmezse cinsel yaşamı olumsuz etkileyeceğini belirtmiştir ${ }^{1}$. Ulusal ve uluslararası literatür incelendiğinde erkeklerin ilk cinsel bilgileri internet ve arkadaşları aracılığıyla öğrendiği görülmüştürr15,19,42-45. Civil ve Yıldız’a göre öğrencilerin yaklaşık yarısı cinsel konuları aileleri ile konuşabiliyorken Apay ve arkadaşlarına göre öğrencilerin yarısından fazlası aileleri ile bu konuları konuşamadığını belirtmiştir42,3. Yapılan bir çalışmada öğrencilerin büyük çoğunluğu cinselliği bir tabu, utanç verici, günahkâr, toplum içinde hatta ebeveynlerle birlikte bile konuşulmayacak bir konu olarak görmektedir. Cinsellik hakkında konuşmanın toplum tarafından dışlanma ile sonuçlanacağını, cinselliğin sadece hemcinsiyle, evli bireylerle, iyi eğitimli ve hoşgörülü bireylerle konuşabilecek bir konu olduğunu vurgulamışlardır31.

Tandoğan ve arkadaşları yaptıkları çalışmada 32-45 yaş aralığında araştırmaya katılan erkekler, cinsel hayatlarında amaçlarının sadece cinsel ilişki olduğu ve hızlı orgazm olmanın cinsel hayatı olumsuz etkilediğini ifade etmişlerdir. Cinsel mitlere inanan erkeklerde cinselliğin yalnızca penetrasyon olarak algılanması ve penetrasyon ile sonlanmayan ilişkinin başarısız kabul edildiği görülmüştür46. Bu çalışmada "Cinsel İlişki” ve "Cinsel Memnuniyet” alt boyutlarında erkeklerin aldığı puanlarda istatistiksel olarak anlamlı bir artışın görülmesi toplumda bu konuda kabul görmüş mitlerin bir yansıması olduğu söylenebilir.

\section{Sonuç ve Öneriler}

Bu araştırma sonucunda erkek öğrencilerin ve ailesi Doğu Anadolu Bölgesi'nde yaşayan öğrencilerin cinsel mitlere inanma düzeylerinin daha yüksek olduğu dikkat çekmektedir. Bu sonuçlara göre;

- Aile içinde kız ve erkek çocuklarına yönelik farklı tutumların engellenmesi amacıyla çocukluk çağında doğru cinsel eğitimin öneminin ebeveynlere anlatılması ve bu konuda gerekli eğitimler düzenlenmesi, 
- Cinsel sağlık dersinin ilk ve orta öğretim müfredatlarına eklenmesi,

- Düzenlenecek cinsel eğitimlerin topluma yönelik değil, yaşanılan bölge ve kültürel farklılıklara özel olarak planlanması önerilmektedir.

\section{KAYNAKLAR}

1. Greenberg JS, Bruess CE, Oswalt SB. Exploring the dimensions of human sexuality. (6rd Ed.) USA: Jones \& Bartlett Learning,2017.

2. WHO(2006).https://www.who.int/reproductivehealth/topics/sexual health/sh definitions/en/ Erişim Tarihi 15 Eylül 2020.

3. Apay SE, Akpınar RB, Arslan S. Öğrencilerin cinsel mitlerinin incelenmesi. Anadolu Hemşirelik ve Sağlık Bilimleri Dergisi. 2013;16(2):96102.

4. Türk Dil Kurumu (TDK). Güncel Türkçe Sözlük. http://www.tdk.gov.tr/index.php?option=com gts\&arama=gts\&guid=TDK.GT S.5c7fge611df877 .40405384. Erişim Tarihi 12 Eylül 2020.

5. Özdemir Ö, Yılmaz M. Sağlık profesyonellerinin cinsel mitlere inanma durumlarının belirlenmesi. Adnan Menderes Üniversitesi Sağlık Bilimleri Fakültesi Dergisi. 2020;4(3):221-232.

6. Hill JC, Graber JA, Jean-Baptiste E, Johnson KJ. Factors associated with attitude- behavior conflicts among sexually experienced, rural, early adolescents. The Journal of Early Adolescence. 2019;39(1):81-96.

7. Kaya A, Boz I. The development of the professional values model in nursing. Nurs Ethics. 2017;26(3):914-923.

8. Öz HG, Sözer GA, Yangın HB. Hemşirelik öğrencilerinin cinsel mitlere inanma durumları ve etkileyen faktörler. Ordu Üniversitesi Hemşirelik Çalışmaları Dergisi. 2020;3(2):136-145.

9. Macintyre AKJ, Montero Vega AR, Sagbakken M. Sexuality? A million things come to mind: Reflections on gender and sexuality by Chilean adolescents. Reproductive Health Matters. 2015;23(46):85-95. 
10. Ashcraft AM, Murray PJ. Talking to parents about adolescent sexuality. Pediatric Clinics. 2017;64(2):305-320.

11. Dhami S, Sheikh A. The Muslim family: Predicament and promise. Western Journal of Medicine. 2000;173(5):352-356.

12. Sharon D, Gonen A, Linetsky I. Factors influencing nursing students' intention to practice sexuality education in their professional work. American Journal of Sexuality Education. 2020;15(3):1-17.

13. Cinsel Sağlık Enstitüsü Derneği (CISED). Cinsel Mitler. http://www.cised.org.tr/sayfa146.html Erişim Tarihi o1 Ekim 2020.

14. Civil B, Yıldız H. Erkek öğrencilerin cinsel deneyimleri ve toplumdaki cinsel tabulara yönelik görüşleri. Dokuz Eylül Üniversitesi Hemşirelik Yüksekokulu Elektronik Dergisi. 2010;3(2):58-64.

15. Torun F, Torun SD, Özaydın AN. Erkeklerde cinsel mitlere inanma oranları ve mitlere inanmayı etkileyen faktörler. Düşünen Adam Psikiyatri ve Nörolojik Bilimler Dergisi. 2011;24(1):24-31.

16. Kukulu K, Gürsoy E, Ak SG. Turkish university students beliefs in sexual myths. Sexuality and Disability. 2009;27(1):49-59.

17. Gölbaşı Z, Evcili F, Eroğlu K, Bircan H. Sexual myths scale [SMS]:

Development, validity and reliability in Turkey. Sexuality and Disability. 2016;34(1):75-87.

18. Evcili F, Gölbaşı Z. Sexual myths and sexual health knowledge levels of Turkish university students. Sexuality \& Culture. 2017;21(4):976-990.

19. Evcili F, Demirel G. Sexual myths of midwifery and nursing students and their attitude regarding the assessment of sexual health. Journal of Human Sciences. 2018;15(4):2280-2288.

20. Hendrickx K, Lodewijckx E, Van Royen P, Denekens J. Sexual behaviour of second generation Moroccan immigrants balancing between traditional attitudes and safe sex. Patient Education and Counseling. 2002;47(2):89-94. 
21. Aker S, Şahin MK, Oğuz G. Sexual myth beliefs and associated factors in university students. Turkish Journal of Family Medicine and Primary Care. 2019;13(4):472-480.

22. Torun F, Torun SD, Özaydın AN. Erkeklerde cinsel mitlere inanma oranları ve mitlere inanmayı etkileyen faktörler. Düşünen Adam Psikiyatri ve Nörolojik Bilimler Dergisi. 2011;24:24-31.

23. Kısa S, Zeyneloğlu S, Yılmaz D, Verim E. Evlilik hazırlığı yapan çiftlerin cinsellikle ilgili bilgi ve inanışları. TAF Prev Med Bull. 2013;12(3):297-306.

24. Ziya ZA. Üniversite Öğrencilerinin Cinsel Mit İnançları, Cinsel Bilgi Düzeyleri ve Cinsel Tutumları Arasındaki İlişkiler [yüksek lisans tezi]. İstanbul, Türkiye: Haliç Üniversitesi Sosyal Bilimler Enstitüsü Psikoloji Anabilim Dalı;2015.

25. Aker S, Böke Ö. The effect of education on the sexual beliefs of family physicians. International Journal of Sexual Health. 2016;28(1):111-116.

26. McMahon S. Rape myth beliefs and bystander attitudes among incoming college students. Journal of American College Health. 2010;59(1):3-11.

27. Lefkowitz E, Shearer C, Gillen M, Espinosa-Hernandez G. How gendered attitudes relate to women's and men's sexual behaviors and beliefs. Sexuality and Culture. 2014;18(4):833-846.

28. Macas Ordoñez EF. Adaptación y Validación de la Sexual Myths Scale en Estudiantes Universitarios Españoles [Trabajo de Fin de Máster]. Universidad de almería, Facultad de Ciencias de la Salud, Máster En Ciencias De La Sexología;2017.

29. Brodwin M, Frederick P. Sexuality and societal beliefs regarding persons living with disabilities. Journal of Rehabilitation. 2010;76:37-41.

30. Hammond MD, Cimpian A. Investigating the cognitive structure of stereotypes: Generic beliefs about groups predict social judgments better than statistical beliefs. Journal of Experimental Psychology: General. 2017;146:607-614.

31. Yılmaz M, Karataş B. Opinions of student nurses on sexual myths; A phenomenological study. Sexuality and Disability. 2018;36(3):277-289. 
32. Constanza S, Castaño JJ, Díaz SA, et al. Prácticas y comportamientos sexuales de estudiantes de la Universidad de Manizales (Colombia) 2010. Psicología desde el Caribe. 2011;28:77-106.

33. Burki T. Health and rights challenges for China's LGBT community. The Lancet. 2017;389(10076):1286.

34. Monto M, Supinski J. Discomfort with homosexuality: A new measure captures differences in attitudes toward gay men and lesbians. Journal of homosexuality. 2014;61(6):899-916.

35. Romero-Sánchez M, Megías JL, Carretero-Dios H, Neira LR. Versión colombiana de la escala Acceptance of modern myths about sexual aggression: primeros análisis psicométricos. Revista Latinoamericana de Psicología. 2013;45(1):121-134.

36. Harakeh Z, De LME, Schrijvers CT, Van Dorsselaer SA, Volleberg WA. Individual and environmental predictors of health risk behaviours among dutch adolescents: The Hbsc study. Public Health. 2012;126:566-573.

37. Al-Quaiz JM, Kazi A, Al-Muneef M. Determinants of sexual health knowledge in adolescent girls in schools of Riyadh-Saudi Arabia: A cross sectional study. BMC Women's Health. 2013;13(1):1-8.

38. Nyoni JE, Ross MW. Condom use and HIV-related behaviors in Urban Tanzanian men who have sex with men: A study of beliefs, HIV knowledge sources, partner interactions and risk behaviors. AIDS Care. 2013;25(2):223229.

39. Bulduk S, Erdoğan S. The effects of peer education on reduction of the HIV/sexually transmitted infection risk behaviors among Turkish University Students. Journal of the Association of Nurses in AIDS Care. 2012;23:233-243.

40. Apay SE, Nagorska M, Akpınar RB, Celik AS, Binkowska-Bury, M. Student comparison of sexual myths: Two-country case. Sexuality and Disability. 2013;31(3):249-262.

41. Aygin D, Açıl H, Yaman O, Çelik Yılmaz A. Üniversitede okuyan kadın öğrencilerin cinsel mitler ile ilgili görüşleri. Androloji Bülteni. 2017;19:44-9. 
42. Civil B, Yıldız H. Male students' opinions about sexual experience and social taboos related to sexuality. DEUHYO ED. 2010;3(2):58-64.

43. Yılmaz E, Zeytinci İE, Sarı S, Karababa İF, Çilli AS, Kucur R. Konya İl Merkezi’nde yaşayan evli nüfusta cinsel sorunların araştırılması. Türk Psikiyatri Dergisi. 2010;21:126-34.

44. Nelson MK, Leickly E, Yang PS, Pereira A, Simoni MS. The influence of sexually explicit online media on sex: Do men who have sex with men believe they "Do what they see"? AIDS Care. 2014;26(7):931-934.

45. Wery A, Bilieux J. Online sexual activities: An exploratory study of problematic and non-problematic usage patterns in a sample of men. Computers in Human Behavior. 2016;56:257-66.

46. Tandoğan Ö, Kaydırak MM, Oskay Ü. Erkeklerin gebelikte cinsel yaşamla ilgili mitleri. Androloji Bülteni. 2019;21:134-139. 